sciendo

\title{
Actualised Infinity: Before-effect and Nullify-effect
}

\author{
Steffen Borge \\ Syracuse University
}

Disputatio No. 8

May 2003

DOI: $10.2478 /$ disp-2003-0002

ISSN: 0873-626X 
Disputatio 14, May 2003

\title{
Actualised infinity: before-effect and nullify-effect
}

\author{
Steffen Borge \\ Syracuse University
}

\section{Introduction}

Can an effect come before its cause? A Zeno-series (Z-series) puzzle introduced by José Benardete suggests that this is metaphysically possible. Benardete suggested that this before-effect is the result of some metaphysical field of force surrounding actualised Z-series. The forces of infinity move in mysterious ways. John Hawthorne has recently revisited Benardete's puzzle and argued that no such dark saying is needed in order to understand the before-effect. The before-effect can be understood as the fusion of the Z-series of actualised infinity causing something to happen. The agents and objects that are affected by a Benardete Z-series are in causal contact with something, namely the fusion of the Z-series, though not in causal contact with any of the parts of the fusion.

Hawthorne's solution to Benardete's puzzle teaches us something about the workings of fusions and their relation to their parts. There are, however, more metaphysical lessons to be learned. After having looked at the puzzle and Hawthorne's solution, I will introduce a new Benardete puzzle. This puzzle is the converse of the original puzzle and gives us the result that even though every single part of a fusion can effectuate a particular result and is in action, the Z-series of them can be causally ineffective. This is what I have dubbed the nullify-effect. The fusion solution introduced by Hawthorne is not suited to deal with the nullify-effect, which means that the puzzles that follow in the slipstream of actualised Z-series have yet to be resolved to our satisfaction. 


\section{Benardete's puzzle}

Some philosophers might consider actual infinity a contentious notion, but how would you exclude it from reality? Do you have an a priori argument for why, as a matter of necessity, there are only a finite number of stars in the sky? Benardete explores some of the consequences of the possibility of actualised infinity and especially that of the before-effect. Here is how the puzzle of the before-effect is introduced in his book Infinity: An Essay in M etaphysics.

Let the peal of a gong be heard in the last half of a minute, a second peal in the preceding $1 / 4$ minute, a third peal in the 1 / 8 minute before that, etc. ad infinitum. (... ) of particular interest is the following case. Let us assume that each peal is so very loud that, upon hearing it, anyone is struck deaf - totally and permanently. At the end of the minute we shall be completely deaf (any one peal being sufficient), but we shall not have heard a single peal! For at most we could have heard only one of the peals (any single peal striking one deaf instantly), and which peal could we have heard? There simply was no first peal. We are all familiar with various physical processes that are followed by what are called after-effects. We are now tempted to coin the barbarous neologism of a before-effect. (Benardete, p. 255-259).

\section{Another example of the before-effect goes as follows:}

A man is shot through the heart during the last half minute by A. B shoots him through the heart during the preceding $1 / 4$ minute, $C$ during the $1 / 8$ minute before that, \&c. ad infinitum. Assuming that each shot kills instantly (if the man were alive), the man must be already dead before each shot. Thus he cannot be said to have died of a bullet wound. Here, again, the infinite sequence logically entails a before-effect. Consider now the following even more radical version of this paradox. A man decides to walk one mile from $A$ to $B$. A god waits in readiness to throw up a wall blocking the man's further advance when the man has travelled 1/ 2 mile. A second god (unknown to the first) waits in readiness to throw up a wall of his own blocking the man's further advance when the man has travelled 1/ 4 mile. A third god... \& C. ad infinitum. It is clear that this infinite sequence of mere intentions (assuming the contrary-to-fact conditional that each god would succeed in executing his intention if given the opportunity) logically entails the consequence that the man will be arrested at point $A$; he will not be able to pass beyond it, even though not a single wall will in fact be thrown down his path. The before-effect here will be 
described by the man as a strange field of force blocking his passage forward (Benardete, pp. 259-260).

Why does the before-effect follow with logical necessity and how are we to explain this monstrous phenomenon? If we cannot avoid admitting it into our metaphysical canon, then how do we explain it?

\section{Unravelling Benardete's puzzle}

Following Hawthorne, the puzzle and its result can be formalised through a series of conditionals along the following lines. Imagine you are walking towards a Z-series of walls. On the closed end, meaning where the walls start, there is a wall that is one meter thick, the next wall is 1 meter from the first wall and $1 / 2$ meter thick, the third wall is $1 / 2$ meter from the second wall and 1/ 4 meter thick, etc. ad infinitum. Every wall has a wall in front of it. There is no last wall. The whole Z-series of walls stretches out from point A, the closed end, to point $B$, the open end. Each wall is such that had you walked into it, it would have stopped you. All walls have been assigned a number. The first wall at the close end of the Z-series is called wall 1, the preceding wall is called wall 2, etc. ad infinitum. Y ou are walking with a continuous momentum and you are going to walk right into the open end of the Z-series of walls. W hat happens?

We can be assured that the following material conditionals are going to hold in this situation mutandis mutadis (see also Hawthorne, pp. 624-625).

C1: If you walk into wall 1, you will not proceed beyond its boundary.

C2: If you walk into wall 2, you will not proceed beyond its boundary.

CN : If you walk into wall n, you will not proceed beyond its boundary. ... and so on.

But, of course, we know that wall 1 has a wall in front of it, namely wall 2, and that wall 2 has a wall in front of it, wall 3, etc. From this we know that:

D1: If you walk into wall 1, you must have walked into wall 2 and proceeded beyond its boundary. 
D2: If you walk into wall 2, you must have walked into wall 3 and proceeded beyond its boundary.

DN: If you walk into wall $n$, you must have walked into wall $n+1$ and proceeded beyond its boundary.

... and so on.

From this we get that:

E1: You do not walk into wall 1.

E2: You do not walk into wall 2.

EN : You do not walk into wall $n$.

... and so on.

The conclusion is clear; you do not walk into any wall. A premise claiming that you walk into a wall straightforwardly leads to a contradiction. Any introduction of such a premise gives us an omega inconsistency. W e know that you are walking in a straight line towards the Zseries of walls with a continuous momentum and given that nothing interferes with your trajectory, even though you hit no wall, you do not proceed beyond point B. But what stops you?

Let us first look at a more radical Benardete puzzle of an actualised Z-series (Benardete, p. 260, Hawthorne, pp. 627-629). I will follow Hawthorne in presenting my version of the case without any conscious or intending agents constituting the Z-series (for such cases, see Benardete's Z-series of wall throwing Gods or Hawthorne's Z-series of machete killers). Imagine that your body has been injected with a Zseries of bacteria that are such that if any one of them in particular is activated you will be killed instantly. Each bacterium has a number and every bacterium has a bacterium that is in front of it in the Z-series. The Z-series of bacteria are such that they will be activated in a particular order between the hours 1 am and 2 am, call these time-points $A$ and $B$. The first bacterium, that is the first one starting at the closed end of the Z-series, is called bacterium 1 and it is so disposed that it will activate at $1.30 \mathrm{am}$, if you are alive at that time. Bacterium 1 is preceded by bacterium 2, which is disposed to activate at $1.15 \mathrm{am}$, if 
you are alive at that time. Bacterium 2 is preceded by bacterium 3 , which is disposed to activate at $1.07,5 \mathrm{am}$, if you are alive at that time, etc. ad infinitum. For every bacterium in the Z-series in your body there is an infinity of other bacteria that are disposed to attack you earlier. What happens then at $1 \mathrm{am}$, when you reach point $A$ ?

$W$ e can at this point rehearse the same line of argument as we did in the case of walking into the Z-series of walls.

C1: If bacterium 1 is activated, you will not survive.

C2: If bacterium 2 is activated, you will not survive.

$\mathrm{CN}$ : If bacterium $\mathrm{n}$ is activated, you will not survive. ... and so on.

But, of course we know that bacterium 1 has a bacterium in front of it, namely bacterium 2, and bacterium 2 has a bacterium in front of it, bacterium 3, etc. From this we know that:

D1: If bacterium 1 is activated, then you must have survived the activation of bacterium 2.

D2: If bacterium 2 is activated, then you must have survived the activation of bacterium 3 .

.

DN: If bacterium $n$ is activated, then you must have survived the activation of bacterium $n+1$.

... and $\mathrm{so}$ on.

And from this we conclude that:

E1: Bacterium 1 is not activated.

E2: Bacterium 2 is not activated.

EN : Bacterium $n$ is not activated. ... and so on. 
No bacterium in the Z-series is activated. A premise stating that a bacterium is activated lands us in a contradiction. The introduction of such a premise will give us an omega inconsistency. W e can al so deduce that if you make it beyond point $A, 1$ am, then a bacterium is activated, but no bacterium is activated so you die before reaching point $A$. But why do you die? All there is in your body is a Z-series of lethal bacteria that are never activated. Each one of them, seen in isolation, remains only potentially lethal. Still by metaphysical necessity their presence kills you. Again there is a mysterious threshold that you will not proceed beyond or reach. But what is it that kills you?

Benardete speaks of the forces of infinity:

The infinite sequence logically entails what we may describe as a field of force which shuts us out from further advance (Benardete, p. 258).

And he adds in a metaphysically pessimistic mood that:

For the cause of this arrest is simply the man's encounter with a field of force, and this field of force is simply the physical equivalent of an omnibus law of nature which is compounded out of an infinite sequence of contrary-to-fact conditions. (... ) Alas. We ourselves would seem to be caught in a fusillade, albeit a fusillade of paradoxes. (Benardete, pp. 260261).

Hawthorne offers a way to see the events of the stopping and the killing that renders them less mysterious.

Consider the fusion of walls. Call it Gordon. On reflection it is clear that the sphere contacts Gordon. Gordon has an open surface. W hen the ball stops proceeding at the one mile mark, there is no unoccupied space between the sphere and Gordon. Contact occurs (which may be open-open or open-closed depending on the nature of the sphere's surface). So the ball is stopped by contact: The ball hits something, though the thing that it hits is not one of the walls (Hawthorne, p. 626).

You are stopped by the fusion of walls. The fusion of an infinite set of walls is itself a concrete thing and thus capable of stopping you. The fusion solution is more ontologically sane and more economic than the positing of infinity force fields. What about the bacteria-case? The same solution is offered for this kind of case. 
By parity of reasoning with the wall case, we can say that the fusion of the assassins cause the assassination of Bob, even though no individual assassin causes the assassination of Bob. (... ) Yet the assassin fusion seems to accomplish effect $c$ without doing anything at all. (That puzzle didn't arise in the wall case because the walls weren't required individually to be able to do anything in order to individually produce the relevant effect, namely stopping the motion of the sphere.) Its not as if there is a super-machete (or its radiatory correlate) that is used to assassinate. If $x$ is the fusion of $y^{\prime} s$ and the $y^{\prime} s$ don't move with respect to $z, x$ doesn't move with respect to $z$. So it follows that the fusion causally secures the assassination of Bob without even moving! Nor does the fusion need to undergo any other type of change at all in order to assassinate Bob (Hawthorne, p. 630).

If you ever wanted a group action, where the action is not reducible to the actions of the individuals in the group, then you have it. In our bacteria case the sheer potentiality among the different bacteria and their organisation, brings about the killing of the organism in which the Z-series of bacteria is found. And so on for the other examples of this kind; the mere intentions of the Gods bring about the action by the fusion, which creates the before-effect and similarly with the machete killers. The resistance we initially feel towards these solutions, however, cries out for an explanation.

\section{Diagnosing Benardete's puzzle}

O ur resistance to the fusion explanation stems, according to Hawthorne, from two widely accepted but mistaken metaphysical principles: the Contact Principle and the Change Principle (Hawthorne, $p$. 626 and p. 630).

THE CONTACT PRINCIPLE: If $y$ is the fusion of $x$ 's and $z$ contacts $y$, then $z$ contacts one of the $x$ 's.

The wall-example shows that this metaphysical principle is false. The bacteria case, of course, also shows this, but it shows more.

THE ChANGE PRINCIPLE: If $x$ is the fusion of $y$ 's and $y$ 's are individually capable only of producing effect e by undergoing change, then $x$ cannot, (without the addition of some non-supervening causal power), produce effect e without undergoing change. 
But as the bacteria case shows, the fusion can produce an effect e, the killing of the organism in which the Z-series of bacteria are implanted, without any part of the fusion or the fusion itself undergoing change. The conclusion to be drawn is that the relations between wholes and parts are, at times, radically different from what we thought they were.

\section{N ullify-effect: a converse Benardete puzzle}

Imagine the following scenario. You are approaching the Z-series of walls. The walls are as described in our previous example. You do not proceed beyond point $B$, the open end of the Z-series of walls, and you make no contact with any particular wall even though you do make contact with the fusion of walls. Recall the organisation of the Z-series of walls. Every wall has a number attached to it, every wall has a wall in front of it, they get thinner and thinner as we move towards the open end, the whole series is exhausted between point $A$ and $B$, etc. Add to this that all the walls are impenetrable, no wall can penetrate another wall and any falling wall that makes contact with another wall will make the other wall fall like a domino. If a falling wall hits you, then you will not survive. Imagine then that wall 1 starts falling towards you, it will then fall on wall 2, which will be set in motion and fall on wall 3, which will be set in motion, etc. ad infinitum. You are standing in contact with the fusion of walls, but no particular wall and they are all falling towards you. W hat will happen? The following material conditionals can be formulated:

C1: If you are hit by wall 1, you will not survive.

C2: If you are hit by wall 2, you will not survive.

$\mathrm{CN}$ : If you are hit by wall n, you will not survive. ... and so on.

But given our premises we also get:

D1: If you are hit by wall 1, then wall 1 must have penetrated wall 2 . 
D2: If you are hit by wall 2, then wall 2 must have penetrated wall 3.

DN : If you are hit by wall $n$, then wall $n$ must have penetrated wall $n+1$. ... and so on.

Every wall in the Z-series is falling towards you ready to deliver a lethal blow, there is no space between you and the fusion of walls and still you could survive. Why?

W e see that you could survive when we draw the following conclusions from the previous material conditionals:

E1: W all 1 does not hit you.

E2: W all 2 does not hit you.

EN : W all $n$ does not hit you.

... and so on.

And if we assume that some wall hits you then we might assume that:

P1: If you are hit by a wall, then for some natural number $n$, wall $n$ hits you.

And if we go one to claim:

P2: A wall hits you.

W e then have a contradiction. You are not hit by any wall whatsoever, but what about the fusion? It is unclear exactly what we want to say here. Possibly the fusion moves, making you move before any wall in particular makes you move and perhaps that will kill you. But it is also possible, or so it seems, that the fusion does not move with respect to you, so that while all the walls in the Z-series of walls fall, the fusion does not, even though all its parts do and you do not die. ${ }^{1}$

${ }^{1}$ Perhaps the geometry of the case will go against the possibility of the fusion not moving. That, how ever, would not exclude the possibility of not having effect e - that you are killed - effectuated. 
We need not decide whether the fusion moves. W hat is more important is that the seemingly inevitable effect e, that you are killed, which every wall or finite series of walls would bring about, is not necessarily effectuated, since no wall hits you. I cannot see what would necessitate effect $e$ in this scenario. This Z-series of falling walls show this to be a metaphysical possibility. If you grant this possibility then it seems that in this scenario it might be the case that if you die then a wall hit you and then we would have an omega inconsistency among our premises.

A critic, however, might want to contest this latest formulation of this imagined scenario. Granted that there is a possibility that the fusion does not move with respect to you, but if you, contrary to fact, die then following Lewis-Stalnaker semantics for subjunctive conditionals it seems that the closest possible world we could envisage that follows my ground rules would be one where the avalanche of walls will knock you to the ground and flatten you (Stalnaker, 1968, Lewis, 1973, Lewis, 1979). The toppling load of walls, e.g. the fusion, will as a logical result of undergoing the domino effect whereby each wall sets the successor wall in motion also, at least, make you move or, perhaps kill you. The fusion of walls is after all, as argued, a physical thing and by parity of reasoning it seems that the closest possible world, relying on Stalnaker's world selection semantics or Lewis' relative similarity semantics for evaluating truth-conditions for subjunctive conditionals, would be one in which you are either merely moved by the fusion or killed by it. A Lewis-Stalnaker analysis of the case in which you die, would be that if you die, there would not have been a wall that killed you. The cause of your death in the nearest possible world would be the fusion of walls.

But this way of handling the problem does not hold in all possible contexts. In particular, it fails, as Jonathan Schaffer has shown, to account for cases of trumping preemption. Here is Schaffer's original example:

Imagine that it is a law of magic that the first spell cast on a given day match the enchantment that midnight. Suppose that at noon Merlin casts a spell (the first that day) to turn the prince into a frog, that at 6:00 pm Morgana cast a spell (the only other that day) to turn the prince into a frog, and that at midnight the prince becomes a frog. Clearly, Merlin's spell (the first that day) is a cause of the prince becoming a frog and Morgana's is not, because the laws say that the first spells are the consequential 
ones. Nevertheless, there is no counterfactual dependence of the prince's becoming a frog on Merlin's spell, because Morgana's spell is a dependency-breaking backup. Further, there is neither a failure of intermediary events along the Morgana process (we may dramatize this by stipulating that spells work directly, without any intermediaries), nor any would-be difference in time or manner of the effect absent Merlin's spell, and thus nothing remains by which extant counterfactual accounts of causation might distinguish Merlin's spell from M organa's in causal status (Schaffer, p. 165). ${ }^{2}$

Let us then consider a somewhat rewritten version of this example. This time the laws of magic state that if a competent magician casts a spell on you any time during the day, it will take effect at midnight, unless some magician cast a similar spell on you later that day, in which case it will have no effect. Imagine then that at $11.30 \mathrm{pm}$ a magician cast a "you will die" spell on you. At 11.45 pm a magician cast a "you will die" spell on you. At 11.52,5 pm a magician cast a "you will die" spell on you, etc. ad infinitum. All spells have a number. Call the spell casted at $11.30 \mathrm{pm}$ spell number 1 , call the spell casted at $11.45 \mathrm{pm}$ spell number 2, etc. Add to this that for every magician there is a magician that cast a similar spell later that day. There is no last spellcasting magician. If you die at midnight, other things being equal, why do you die? Is it because spell number 1 took effect? But spell number 1 was trumped by a later spell, namely spell number 2 , which in turn was trumped by spell number 3 , etc. ad infinitum for the Z-series of spells. You end up surviving even though infinitely many magicians tried to kill you, and any one of them or any finite series of them operating in anything but a Z-series of spell-casting magicians would have be capable of doing so. Here we have a clear case of an infinite chain of events that does not kill you, even if each one of them taken in isolation or in a finite series would have. The fusion of spells does not have any effect, because that is how the laws of magic work.

\footnotetext{
${ }^{2}$ It is beyond the scope of this paper to carefully discuss Lewis' response to this problem as found in Lewis 2000. I believe, how ever, that Collins is right when he points out that Lewis' response to Schaffer amounts to a change of topic from the old question of "W hat is it for this event to be a cause of that event?" to a quite new question of "W hat is it for this event to have a causal influence on that event?" (Collins, pp. 230-231). And as such, Schaffer's challenge remains.
} 
By parity of reasoning we might want to say that something similar goes on in the case of the Z-series of falling walls. The Z-series of falling walls could be made out to be a special case of Schaffer's trumping preemption. The countervailing forces in the wall example are just the presence of an impenetrable wall in front of any wall. We might imagine, to make the analogy even clearer, that each wall in the Zseries of walls is so tall that had it not had another wall in front of it and it started falling, it would have fallen on you and killed you. In the same way as spell number 1 would have killed you, in the magician example, had none of the other spells been cast that day, wall number 1 would have killed you had there been no other walls in front of it. But you will not necessarily be killed in the magician case, since for any particular spell there is a spell that is cast later that day, and you will not necessarily be killed in the walls case, since for any particular wall there is a wall in front of it.

What then prevents the walls from killing you (or even moving you) in this possible scenario? Is there any temptation here to say that just as the fusion has the power to prevent you from proceeding beyond point B and make contact with a wall, the causal power of the fusion also keeps the walls safely in line preventing them from exercising their individual causal powers? W hatever one wants to say about the fusion of the walls and whether it makes you move or not, it is clear that the effect e of killing you is not necessarily brought about, even if every single wall or finite series of walls would, had it not been caught in a Z-series of walls of this kind. If this is true, then why not admit that it is possible that the effect of making you move, which also some wall or another would have effectuated had it operated in any other configuration of walls, is also cancelled out? Some of the walls' causal powers with respect to you are cancelled out, why not all? W hat would explain this asymmetry? Mysterious as this is, at least the thought that not only do you survive, but nothing makes you move has the virtue of consistency in the treatment of the particular walls' causal efficiency. Mimicking Benardete, we attach to this effect, the cancelling out effect, the barbarous neologism of a nullify-effect.

W e can also rehearse a converse case of the bacteria case, bringing even clearer into focus how the nullify-effect works in Z-series. This is perhaps a less controversial example of the possibility of the nullifyeffect, since no talk of laws of magic, or walls if you like, is needed in order to see how the nullify-effect comes about. Again we find that the same phenomenon, the lethalness of the activation of all bacteria will 
be nullified by the Z-series of bacteria. Assume the same scenario, only this time the activation of a bacterium will not kill you immediately. The Z-series of bacteria is spatially located in your body (parity with the organisation of the Z-series of walls) and we activate the first bacterium at the closed end of the series. Bacterium 1 will be immediately lethal on activation unless, there is another bacterium, bacterium 2 , in which case bacterium 2 is activated. Bacterium 2 will be immediately lethal on activation, unless there is another bacterium in front of it, in which case that bacterium will be activated, etc. ad infinitum. Every bacterium has a bacterium in front of it and any particular bacterium remains active after activation though not necessarily lethal. Again the same curious result obtains. Even though all lethal bacteria in your body are activated and any one of them or any finite series of them is capable of bringing about an effect $e$, being lethal, the effect $e$ is nullified by the Z-series of activated bacteria. The causal killing powers of each individual bacterium or finite series of bacteria are nullified by the Z-series of bacteria, so that the effect e of killing you does not come about.

Notice that the nullify-effect is a result of the organisation of the bacteria only, e.g. the fact that they constitute a Z-series of bacteria. The nullify-effect is not due to some extra causal powers these bacteria have to cancel out each other's killing powers when operating in symphony. How so? Even though it is the case that for any bacterium the presence of a subsequent bacterium neutralises or puts on hold the killing power of that earlier bacterium, you still die if the series of bacteria is finite. In any finite series of bacteria there is a last bacterium in the series that gets activated, which kills you. In any finite series of bacteria that follows the rules of our example, we would have add extra causal powers to the bacteria in order for them to completely neutralise their lethalness. It is not so with the Z-series of bacteria. There is no need in the latter example to add anything to the bacteria's causal powers to get the nullify-effect, all you have to do is to organise them in a Z-series of the described kind. Similar remarks hold for the falling walls and the spell-casting magicians. So again we have a case, like the Z-series of falling walls and the Z-series of spell-casting magicians, of the possibility of an infinite chain of events that does not kill you, even if each one of them taken in isolation or in a finite series would have.

Why do we want to resist the conclusion that there could be a nullify-effect of the described kind for Z-series of actualised infinity? 
First; if this is a converse of the first Benardete puzzle of the walls and that puzzle refuted the change principle, then our new puzzle should refute a converse of the change principle.

The ChANGe PRInCIPLE*: If $x$ is a fusion of $y^{\prime} s$ and $y$ 's are individually capable of producing effect e by undergoing change $f$, then if all $y$ ' $s f$, (without the addition of some extra causal powers of f-ing y's to neutralise all f-ing $y^{\prime} s$ causal power to bring about e), then $x$ will $f$ and bring about $e$.

If any individual wall or ordinary series of walls falls towards you, then it will kill you. And any ordinary fusion of walls would undergo the same change and bring about the same result. But this is not the case with the Z-series of walls, the Z-series of bacteria and Z-series of magicians. There are of course cases where a certain entity has the causal power to bring about an effect $\mathrm{e}$, but where this causal power is neutralised if it operates in symphony with other entities of the same kind. In such a case, however, we would have to point to extra causal powers in the entities that connect causally with the other entities capacity to bring about such an effect for the cancelling of causal powers to occur. Granted that as long as we cannot perform experimental metaphysics, it cannot be ruled out that this is the right diagnosis of the nullify-effect. But the move is unmotivated. There is no need to appeal to such extra causal powers of the entities we are discussing in order to see how this cancelling out effect obtains. The mere organisation, actualised infinity, of say, the bacteria, gives us the nullify effect. The converse Change Principle, our Change Principle* is false.

The nullify-effect shows that the converse of the Change Principle is false, just like the before-effect shows that the Change Principle is false. You might then expect that since the before-effect renders the Contact Principle false, the nullify-effect will falsify the converse of the Contact Principle. But that is not the case. What would the converse of the Contact Principle look like?

CONTACT PRINCIPLE*: If $y$ is the fusion of $x$ 's and $z$ contacts one of the $x^{\prime} s$, then $z$ contacts $y$.

This principle is sound. There is no way as far as I can see to construe an example that shows the falsity of the Contact Principle*, even though the original Contact Principle has to be abandoned in light of the possibility of actual Z-series of the Benardete kind. 
W hat then is the lesson, if any, to be learned from these examples, and the failure of symmetry in our investigation? Hawthorne's solution to Benardete's puzzle is now, I suggest, in danger of loosing its generality.

\section{Back to the drawing board}

The reason for endorsing Hawthorne's explanation of the beforeeffect was that it had less ontological import; no mysterious infinity forces at work only a surprising result about how fusions work. But there is more; considerations about contact also favour Hawthorne's solution.

It is an undeniable fact that in the original case of a Z-series of walls you must make contact with something. In considering what contact amounts to and under the assumption that space is continuous $\mathrm{Haw}$ thorne suggests three possibilities for how we ordinarily think about contact (Hawthorne, p. 626).

A closed surface contacts an open surface insofar as there is no unoccupied space in betw een the two surfaces. Call this closed-open contact.

An open surface contacts an open surface insofar as there is no more than a line's breadth of unoccupied space between them (the line can then be called the boundary of the two surfaces). Call this open-open contact.

A closed surface contacts a closed surface insofar as the outer skin of each overlaps. Call this closed-closed contact.

These are the options for contact between things. All things, of course, have either a closed or an open surface. The original case of a Z-series of walls is a case of a closed surface, namely you, coming in contact with an open surface, the Z-series of walls. Benardete's infinity force fields do not fit the situation, but the fusion of the walls does without violating any of the premises in the example. So you walk into the fusion, but none of the walls and that accounts for this example of the before-effect. Y ou are stopped by the fusion before you reach any point where you might have encountered a wall and this fits nicely with our way of thinking about contact.

But notice that no such convincing line of argument has been given for the other cases, the case with the bacteria, the wall throwing Gods 
and the machete killers. W e are invited to accept the fusion solution as applicable to these cases by parity of reasoning. As long as there was only one other type of case to be dealt with that invitation was tempting, but now we have a new kind of puzzle on our hands. Is there any temptation to say that the nullify-effect is caused by the fusion acting inwards on its parts? D oes thinking about the fusions in these cases help us understand the nullify-effect? No. Granted, the fusion solution deals with one kind of before-effect, but it is also clear that the before-effect and the nullify-effect are two sides of the same metaphysical coin. It is reasonable to assume that they are in root the results of the same kind of phenomenon. But the fusion solution leaves us in the dark about what the explanation of the nullify-effect would look like. This then should incline us to reject Hawthorne's invitation to treat the other kinds of before-effects as parallel, to the one before-effect, which the fusion solution can deal with. The fusion solution does not explain before-effect simpliciter. Any such explanation must explain both the before-effect and the nullify-effect.

The before-effect simpliciter and the nullify-effect simpliciter indicate that there is some kind of metaphysical threshold between the inside and the outside of actualised Z-series. The Z-series acts, either passively, stopping things or actively, by annihilating things, and there is a resistance within the Z-series that prevents certain actions from taking place. O ne is tempted to invoke Benardete's metaphor about there being a field of force around actualised Z-series. This then makes the actualised Z-series the mysterious creatures of darkness that Benardete thought they were. But all is not lost. Hawthorne's partial solution has wrestled some of the mystery out of the Benardete puzzles, but more work is needed before this metaphysical thriller can come to a final showdown. ${ }^{3}$

Steffen Borge

Department of Philosophy

$541 \mathrm{Hall}$ of Languages

Syracuse U niversity, Syracuse, NY, 13244

steffenborge@ yahoo.com

${ }^{3}$ I thank José Benardete, John Hawthorne, Mark Scala, Ted Sider, Brian W eatherson and Dean Zimmerman for helpful and illuminating comments on earlier drafts of this paper. 


\section{References}

Benardete, J. (1964). Infinity: An Essay in Metaphysics. Oxford, Clarendon Press.

Collins, J. (2000). "Preemptive Prevention". The Journal of Philosophy, Vol. 97, No. 4, pp. 165-181.

Hawthorne, J (2000). "Before-Effect and Zeno Causality". Nous, Vol. 34, No. 4, pp. 622-633.

Lewis, D. (1973). Counterfactuals. Oxford, Blackwell.

Lewis, D. (1979). "Counterfactual Dependence and Time's Arrow". Reprinted in Lewis, D. 1986, Philosophical Papers, Vol. II, Oxford, 0 xford U niversity Press.

Lewis, D. (2000). "Causation as Influence". The Journal of Philosophy, Vol. 97, N o. 4, pp. 182-197.

Schaffer. J. (2000). "Trumping Preemption". The Journal of Philosophy, Vol. 97, N o. 4, pp. 165-181.

Stalnaker, R. (1968). "A Theory of Conditionals". In Rescher, N. (ed.) Studies in Logical Theory, 0 xford, Blackwell. 